\title{
Meta-analysis of radiofrequency ablation versus hepatic resection for small hepatocellular carcinoma
}

Yanming Zhou ${ }^{\dagger 1,4}$, Yanfang Zhao ${ }^{+2}$, Bin Li+1, Donghui Xu' , Zhengfeng Yin³ , Feng Xie ${ }^{4}$ and Jiamei Yang*4

\begin{abstract}
Background: There is no clear consensus on the better therapy [radiofrequency ablation (RFA) versus hepatic resection (HR)] for small hepatocellular carcinoma (HCC) eligible for surgical treatments. This study is a meta-analysis of the available evidence.

Methods: Systematic review and meta-analysis of trials comparing RFA with HR for small HCC published from 1997 to 2009 in PubMed and Medline. Pooled odds ratios (OR) with 95\% confidence intervals (95\% Cl) were calculated using either the fixed effects model or random effects model.

Results: One randomized controlled trial, and 9 nonrandomized controlled trials studies were included in this analysis. These studies included a total of 1411 patients: 744 treated with RFA and 667 treated with HR. The overall survival was significantly higher in patients treated with HR than in those treated with RFA at 3 years (OR: $0.56,95 \%$ Cl: 0.44-0.71), and at 5 year (OR: 0.60, 95\% Cl: 0.36-1.01). RFA has a higher rates of local intrahepatic recurrence compared to HR (OR: 4.50, 95\% Cl: 2.45-8.27). In the HR group the 1,3, and 5 years disease -free survival rates were significantly better than in the HR-treated patients (respectively: OR: 0.54, 95\% Cl: 0.35-0.84; OR: 0.44, 95\% Cl: 0.28-0.68; OR: 0.64, 95\% Cl: 0.42-0.99). The postoperative morbidity was higher with HR (OR: $0.29,95 \%$ Cl: 0.13-0.65), but no significant differences were found concerning mortality. For tumors $\leq 3 \mathrm{~cm}$ HR did not differ significantly from RFA for survival, as reported in three NRCTs.

Conclusions: HR was superior to RFA in the treatment of patients with small HCC eligible for surgical treatments, particularly for tumors $>3 \mathrm{~cm}$. However, the findings have to be carefully interpreted due to the lower level of evidence.
\end{abstract}

\section{Background}

Hepatocellular carcinoma (HCC) is the fifth most common cancers in the world, with an estimated 500,000 deaths per year [1]. Advances in diagnostic imaging and widespread application of screening programs in highrisk populations have allowed detection of small HCC, which can be curable by partial hepatic resection (HR), liver transplantation, or local ablation therapies. Out of these, liver transplantation, which offers the potential to both resect the entire potentially tumor-bearing liver and eliminate the cirrhosis, achieves the best results but can be offered only to a minority of patients because of the

* Correspondence: yjm.1952@yahoo.com.cn

4 Department of Special Treatment, Eastern Hepatobiliary Surgery Hospital,

Second Military Medical University, Shanghai, China

+ Contributed equally

Full list of author information is available at the end of the article shortage of donors and high cost [2]. Therefore, HR has generally been accepted as the first treatment of choice for HCC in many centers. Nevertheless, the associated cirrhosis limits the extent of surgery and thus increases the risk of postoperative liver failure. So, many nonsurgical ablative methods have been developed, such as cryoablation [3], percutaneous ethanol injection (PEI) [4], acetic acid injection [5], radiofrequency ablation (RFA) [6], microwave coagulation [7], and transcatheter arterial chemoembolization (TACE) [8].

Among these therapies, RFA is a promising and recently developed ablation technique. It induces deep thermal injury in hepatic tissue while sparing the normal parenchyma. Its basic principle includes generation of high-frequency alternating current which causes ionic agitation and conversion to heat, with subsequent evapo- 
ration of intracellular water which leads to irreversible cellular changes, including intracellular protein denaturation, melting of membrane lipid bilayers, and coagulative necrosis of individual tumor cells. RFA was recommended as the best treatment option for patients with early stage HCC who are not suitable for resection or transplantation in addition to PEI in the 2005 practice guidelines issued by the American Association for the Study of Liver Diseases [9]. Recently, a meta-analysis of randomized controlled trial (RCT) showed that RFA ablation is superior to PEI in the treatment of patients with relatively preserved liver function and early-stage non-surgical HCC with respect to survival and local control of the disease [10]. In contrast, whether RFA or HR is the better treatment for HCC eligible for surgical treatments has long been debated. Several RCT and non-randomized controlled trial (NRCT) have been published in an attempt to answer the above question. What follows is a meta-analysis of these studies.

\section{Methods \\ Study selection}

Electronic searches were performed of the PubMed and Medline from January 1997 to November 2009. The following Mesh search headings were used: "radiofrequency ablation," "hepatocellular carcinoma". Reference lists of all retrieved articles were manual searched for additional studies. No language restrictions were made.

\section{Data extraction}

Two reviewers (BL and DX, respectively) independently extracted the following parameters from each study: 1) first author and year of publication; 2) number of patients, patients characteristics, study design; and lastly, 3) treatment outcome. All relevant text, tables and figures were reviewed for data extraction. Discrepancies between the two reviewers were resolved by discussion and consensus.

\section{Criteria for inclusion and exclusion}

For inclusion in the meta-analysis, a study had to fulfil the following criteria: 1) compare the initial therapy effects of RFA and HR for the treatment of small HCC, regardless of the etiology of liver disease, cirrhotics status, or differences in viral hepatitis; 2) report on at least one of the outcome measures mentioned below; 3) clearly document indications for RFA and HR; 4) In dual (or multiple) studies were reported by the same institution and/or authors, either the one of higher quality or the most recent publication was included in the analysis. The primary endpoints were overall survival at 1, 3, and 5 years, and local recurrence. The secondary endpoints were disease-free survival at 1,3 , and 5 years, morbidity, and mortality.
Small HCC are defined according to the criteria developed by Yao et al. [11] from the University of California, San Francisco, a single HCC nodule of up to $6.5 \mathrm{~cm}$, or with up to 3 lesions, the largest of which is no larger than $4.5 \mathrm{~cm}$.

Abstracts, letters, editorials and expert opinions, reviews without original data, case reports and studies lacking control groups were excluded. The following studies were also excluded: 1) those dealing with unresectable HCC or HCC recurrence after hepatectomy; 2) those with no clearly reported outcomes of interest; 3 ) those evaluating patients with cholangiocellular carcinomas or liver metastases.

\section{Statistical methods}

The meta-analysis was performed using the Review Manager (RevMan) software, version 4.2.7. All analyses were performed on dichotomous outcomes. Pooled odds ratios (OR) with 95\% confidence intervals (95\% CI) were calculated using either the fixed effects model or random effects model. Heterogeneity was evaluated by $\mathrm{X}^{2}$ and $\mathrm{I}^{2}$. $\mathrm{I}^{2}<25 \%$ and $\mathrm{I}^{2}>50 \%$ reflect small and large inconsistency, respectively. $P<0.05$ was considered significant.

\section{Results}

\section{Selection of trials}

After initial screening, 19 potentially relevant clinical trials of HCC were identified. Of these, three trials did not separately analyze the results of RFA from the other local therapies [12-14], two trials including patients with unresectable HCC $[15,16]$, one trial comparing resection with RFA combined with preceding TACE [17], all 6 studies were excluded. Three trials were also excluded from the analysis, as no information concerning 3 or 5 -year overall survival was provided in these trials [18-20]. Finally, a total of 10 studies (1 RCT and 9 NRCTs) [21-30] published between 2004 and 2009 matched the selection criteria and were therefore included. Eight of these studies used percutaneous RFA [21-28], and the remaining 2 studies used laparoscopic RFA [29,30]. These studies included a total of 1411 patients: 744 treated with RAF and 667 treated with HR. The mean age ranged from 49.2 \pm 9.9 to $69.4 \pm 9.1$ years. Male: female ratio in the pooled data was 2.4: 1. 84.7\% of patients were in Child-Pugh class A. Most patients $(91.0 \%, 1139 / 1251)$ had a single tumor. The median/mean tumor size $(\mathrm{cm})$ ranged from 1.98 to 3.65. Median/mean duration of follow-up ranged from 21.9 to 43 months (Table 1 ).

\section{Overall survival}

There was no significant difference in overall survival between the two groups at 1 year (all trials reported this data, OR: 0.84, 95\% CI: 0.58-1.21), and at 2 years (four trials reported this data, OR: 0.80, 95\% CI: 0.50-1.27), 
Table 1: Characteristics of included trials

\begin{tabular}{|c|c|c|c|c|c|c|c|c|c|c|}
\hline Author/(year) & Design & Inclusion criteria & Treatment & $\begin{array}{l}\text { No. of } \\
\text { patients }\end{array}$ & $\mathbf{M} / \mathbf{F}$ & $\begin{array}{l}\text { Mean age } \\
\text { (years) }\end{array}$ & $\begin{array}{l}\text { Mean tumor } \\
\text { size }(\mathrm{cm})\end{array}$ & $\begin{array}{l}\text { Mean AFP } \\
(\mathrm{ng} / \mathrm{ml})\end{array}$ & Child-Pugh A/B & $\begin{array}{l}\text { Mean follow-up } \\
\text { (months) }\end{array}$ \\
\hline Vivarelli & $\mathrm{NRCT}$ & (1)cirrhosis; (2)Child-Pugh class A or B & RFA & 79 & $67 / 12$ & $67.8 \pm 8.7$ & -- & $>20(n=26)$ & $43 / 36$ & $15.6 \pm 11.7$ \\
\hline (2004) & & & $\mathrm{HR}$ & 79 & $57 / 22$ & $65.2 \pm 8.2$ & -- & $>20(n=43)$ & $70 / 9$ & $28.9 \pm 17.9$ \\
\hline Hong & $\mathrm{NRCT}$ & $\begin{array}{l}\text { (1) patients with liver cirrhosis whose Child-Pugh score } \\
\text { is } 5 \text { or those without cirrhosis; (2)solitary tumor }<4 \mathrm{~cm} \text {; } \\
\text { (3) no vascular invasion; (4) no previous treatment }\end{array}$ & RFA & 55 & $41 / 14$ & $59.1 \pm 9.6$ & $2.4 \pm 0.6$ & $447.3 \pm 981.3$ & $55 / 0$ & $22.7^{*}$ \\
\hline$(2005)$ & & & $\mathrm{HR}$ & 93 & $69 / 24$ & $49.2 \pm 9.9$ & $2.5 \pm 0.8$ & $644.0 \pm 1745.6$ & $93 / 0$ & 25.5 \\
\hline Cho & NRCT & $\begin{array}{l}\text { (1)Single or multiple ( } \leq 3 \text { nodules) } \leq 5 \mathrm{~cm} \text {; (2) Pugh- } \\
\text { Child Class A; (3) no extrahepatic metastasis }\end{array}$ & RFA & 99 & $76 / 23$ & 58 & $3.1 \pm 0.8$ & -- & $99 / 0$ & $23 \pm 9.4$ \\
\hline (2005) & & & $\mathrm{HR}$ & 61 & $48 / 13$ & 57 & $3.4 \pm 1$ & -- & $61 / 0$ & $21.9 \pm 9.8$ \\
\hline Montorsi & $\mathrm{NRCT}$ & $\begin{array}{l}\text { (1) Cirrhosis (2)Solitary tumor } \leq 5 \mathrm{~cm} \text {. single lesion; (3) } \\
\text { Child A-B class; (4) segmental or subsegmental } \\
\text { resection possible; (5) no previous treatment }\end{array}$ & RFA & 58 & $43 / 15$ & $67 \pm 6$ & -- & $377.7 \pm 1051.8$ & $40 / 18$ & $25.7 \pm 16.7$ \\
\hline (2005) & & & $\mathrm{HR}$ & 40 & $33 / 7$ & $67 \pm 9$ & -- & $361.3 \pm 1026.2$ & $32 / 8$ & $22.4 \pm 17.5$ \\
\hline Chen & RCT & $\begin{array}{l}\text { (1) age } 18 \text { to } 75 \text { years; (2) solitary tumor } \leq 5 \mathrm{~cm} \text {; (3)no } \\
\text { extrahepatic metastasis; (4) Pugh-Child Class A, with } \\
\text { no history of ncephalopathy, ascites refractory to } \\
\text { diuretics, or variceal bleeding; (5) ICG-R15 }<30 \% \text {; }(6) \text { no } \\
\text { previous treatment }\end{array}$ & RFA & 71 & $56 / 15$ & $51.9 \pm 11.2$ & -- & $>200(n=31)$ & $71 / 0$ & $27.9 \pm 10.6$ \\
\hline (2006) & & & $\mathrm{HR}$ & 90 & $75 / 15$ & $49.4 \pm 10.9$ & -- & $>200(n=30)$ & $90 / 0$ & $29.2 \pm 11.9$ \\
\hline Lupo & NRCT & $\begin{array}{l}\text { (1) Single tumor } 3-5 \mathrm{~cm} \text {; (2) no previous treatment; ( } 3 \text { ) } \\
\text { no extrahepatic metastasis; (4) Child-Pugh class A or B }\end{array}$ & RFA & 60 & $47 / 13$ & 68 & $3.65^{*}$ & $>200(n=3)$ & $44 / 16$ & $27 \pm 18.7$ \\
\hline (2007) & & & $\mathrm{HR}$ & 42 & $33 / 9$ & 67 & 4 & $>200(n=5)$ & $28 / 14$ & $31.3 \pm 24.3$ \\
\hline Guglielmi & $\mathrm{NRCT}$ & $\begin{array}{l}\text { (1)Cirrhosis; (2)Single or multiple ( } \leq 3 \text { nodules) } \leq 6 \mathrm{~cm} \text {; } \\
\text { (3)Child-Pugh class A or B }\end{array}$ & RFA & 109 & $88 / 21$ & -- & -- & $>200(n=43)$ & $64 / 45$ & 23 \\
\hline (2008) & & & $\mathrm{HR}$ & 91 & $73 / 18$ & -- & -- & $>200(n=34)$ & $69 / 22$ & 32 \\
\hline Hiraoka & $\mathrm{NRCT}$ & (1) Single tumor $\leq 3 \mathrm{~cm}$; & RFA & 105 & $76 / 29$ & $69.4 \pm 9.1$ & 1.98 & 114.5 & $79 / 26$ & $847 \$$ \\
\hline (2008) & & (2) Child-Pugh class A or B & $\mathrm{HR}$ & 59 & $44 / 15$ & $62.4 \pm 10.6$ & 2.27 & 427.8 & $54 / 5$ & 927 \\
\hline Abu-Hila & NRCT & (1)Cirrhosis; & RFA & 34 & $27 / 7$ & 65 & $3^{*}$ & -- & $27 / 7$ & $30^{*}$ \\
\hline (2008) & & (2) Single tumor $1-5 \mathrm{~cm}$. & $\mathrm{HR}$ & 34 & $26 / 8$ & 67 & 3.8 & -- & $25 / 9$ & 43 \\
\hline Santambrogio & NRCT & (1)Single tumor $<5 \mathrm{~cm}$; (2)Child-Pugh class A & RFA & 74 & $59 / 15$ & $68 \pm 7$ & 2.66 & 9 & $74 / 0$ & $38.2 \pm 28.4$ \\
\hline (2009) & & & $\mathrm{HR}$ & 78 & $55 / 23$ & $68 \pm 8$ & 2.91 & 8 & $78 / 0$ & $36.2 \pm 23.5$ \\
\hline
\end{tabular}

RCT: randomised controlled trial. NRCT: non-randomized controlled trial. AFP: alpha-fetoprotein. RFA: radiofrequency ablation. HR: hepatic resection. M: male. F: female. *: median. \$: Day. 


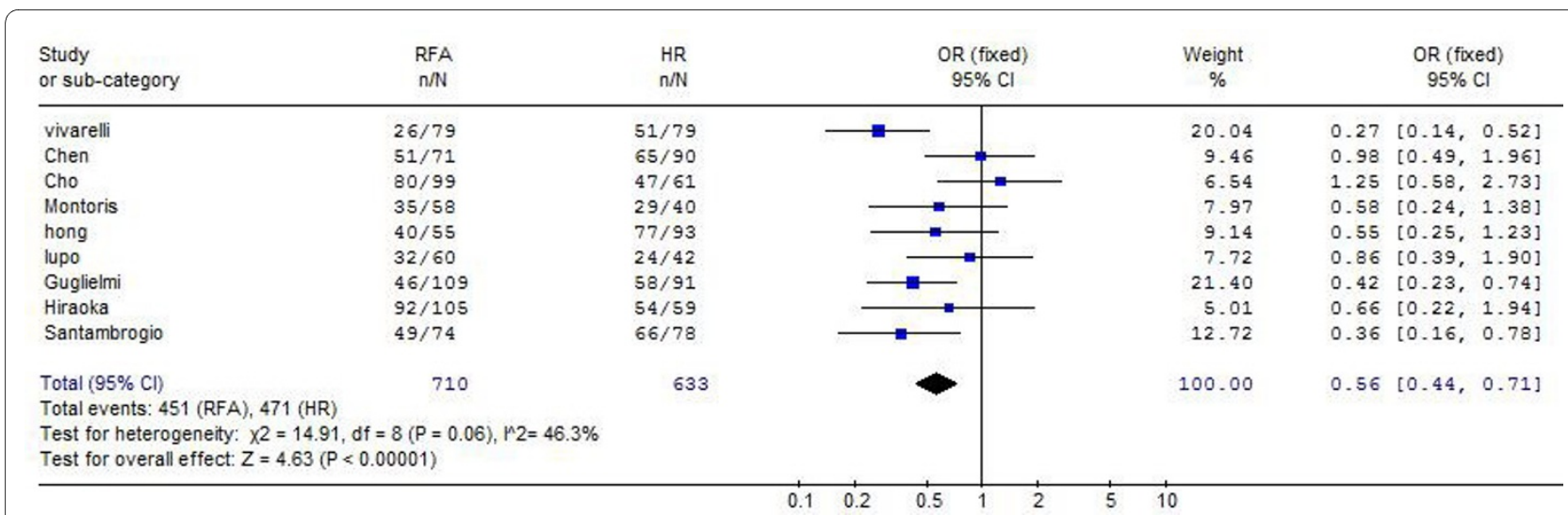

Figure 1 Results of the meta-analysis on overall survival at 3 years.

whereas the difference was significant and favourable to HR group at 3 years (nine trials reported this data, OR: $0.56,95 \%$ CI: 0.44-0.71) ( Figure 1), and at 5 year (five trials reported this data, OR: 0.60, 95\% CI: 0.36-1.01) (Table 2).

\section{Intrahepatic recurrence}

The pooled analysis of the 5 studies furnishing data showed that RFA has a higher rates of local intrahepatic recurrence compared to $\mathrm{HR}$ (OR: 4.50, 95\% CI: 2.45-8.27) (Figure 2). No differences were found between the two groups with respect to the distant intrahepatic recurrence (Table 2).

\section{Disease-free survival}

As Table 2 shows, our results indicate that 1,3 and 5 year disease-free survival rates were significantly higher in the HR group.

Table 2: Summary of the results on the efficacy and safety of RFA versus HR in the management of small HCC

\begin{tabular}{|c|c|c|c|c|c|c|}
\hline \multirow[t]{2}{*}{ Variables } & \multirow{2}{*}{$\begin{array}{l}\text { No. of studies } \\
\text { furnishing data }\end{array}$} & \multicolumn{2}{|r|}{ Results } & \multirow[t]{2}{*}{ OR $(95 \% \mathrm{Cl})$} & \multirow[t]{2}{*}{$P$-value } & \multirow[t]{2}{*}{12} \\
\hline & & RFA & HR & & & \\
\hline \multicolumn{7}{|l|}{ Efficacy: } \\
\hline \multicolumn{7}{|l|}{ Overall survival } \\
\hline 1 year & $10^{21-30}$ & $89.7 \%$ & $91.3 \%$ & $0.84(0.58,1.21)$ & 0.34 & $0 \%$ \\
\hline 2 years & $4^{23-25,29}$ & $79.3 \%$ & $82.2 \%$ & $0.80(0.50,1.27)$ & 0.35 & $0 \%$ \\
\hline 3 years & $9^{21-28,30}$ & $63.5 \%$ & $74.4 \%$ & $0.56(0.44,0.71)$ & $<0.001$ & $46.3 \%$ \\
\hline 5 years & $5^{26-30}$ & $41.3 \%$ & $51.9 \%$ & $0.60(0.36,1.01)$ & 0.05 & $61.6 \%$ \\
\hline \multicolumn{7}{|l|}{ Intrahepatic recurrence } \\
\hline Local recurrence & $522-24,29,30$ & $19.0 \%$ & $4.2 \%$ & $4.50(2.45,8.27)$ & $<0.001$ & $10.7 \%$ \\
\hline Distant recurrence & $522-24,29,30$ & $39.6 \%$ & $38.8 \%$ & $1.16(0.83,1.61)$ & 0.38 & $27.1 \%$ \\
\hline \multicolumn{7}{|l|}{ Disease-free survival } \\
\hline 1 year & $9^{21-29}$ & $68.8 \%$ & $80.3 \%$ & $0.54(0.35,0.84)$ & 0.006 & $59.2 \%$ \\
\hline 2 years & $3^{24,25,29}$ & $49.6 \%$ & $74.3 \%$ & $0.34(0.21,0.55)$ & $<0.001$ & $0 \%$ \\
\hline 3 years & $8^{21-28}$ & $34.9 \%$ & $54.4 \%$ & $0.44(0.28,0.68)$ & $<0.001$ & $66.7 \%$ \\
\hline 5 years & $4^{25-28}$ & $18.4 \%$ & $23.8 \%$ & $0.64(0.42,0.99)$ & 0.05 & $47.2 \%$ \\
\hline \multicolumn{7}{|l|}{ Safety: } \\
\hline Morbidity & $623,25,26,27,29,30$ & $9.6 \%$ & $32.5 \%$ & $0.29(0.13,0.65)$ & 0.003 & $72.7 \%$ \\
\hline Mortality & $10^{21-30}$ & $0.1 \%$ & $0.8 \%$ & $0.36(0.10,1.27)$ & 0.11 & $0 \%$ \\
\hline
\end{tabular}

RFA: radiofrequency ablation.HR: hepatic resection. OR: odds ratios. 


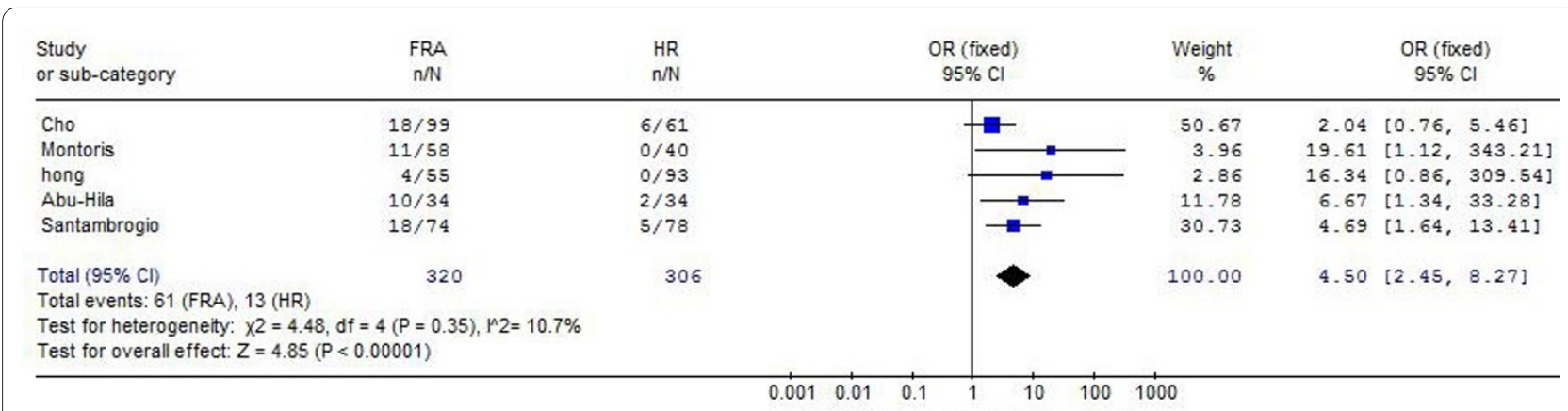

Figure 2 Results of the meta-analysis on local recurrence rate

\section{Safety}

The rate of postoperative morbidity was significantly higher in patients treated with HR than in those treated with RFA (six trials reported this data, OR: 0.29, 95\% CI: 0.13-0.65), but no differences were found between the two groups with respect to postoperative mortality (all trials reported this data, OR: 0.36, 95\% CI: 0.10-1.27). There were 1 death reported in the RFA group, and 6 in the HR group, giving a mean mortality rate of 0.1 per cent and 0.8 per cent, respectively (Table 2 ).

\section{Comparison between the two groups in $\mathrm{HCCs} \leq 3 \mathrm{~cm}$}

Three NRCTs compared RFA versus HR for patients with tumors $\leq 3 \mathrm{~cm}$. Of these, two studies included only patients with single tumor $[27,28]$. There was no significant difference in overall and disease -free survival between the groups at 1,3 , and 5 years in each included study (Table 3). In the further analysis, survival of patients with single or multiple tumors was similar in the two treatment groups, as reported by Vivarelli et al. [21]. Thus, we did not perform a meta-analysis of these studies.

\section{Discussion}

Meta-analysis, a quantitative technique for therapeutic evaluation, may be used when controversy persists after several trials. Although meta-analysis has traditionally been applied and is best confined to RCT, meta-analytical techniques using NRCT might be a valid method in some clinical settings in which either the number or the sample size of RCT is insufficient [31].

This meta-analysis shows that in patients with small HCC the treatment with HR is superior to treatment with RFA. HR had a significant better survival in terms of overall survival at 3 , and 5 years, and disease-free survival at 1,3 , and 5 years. The difference at 5 years overall survival was marginally significant due to the number of studies furnishing combinable data on this outcome is limited. Although the only RCT shows nearly equivalent survival with the two treatments, however, in this study 19 of 90 patients (21\%) who were randomized for RFA converted to HR [25].

High rate of intrhepatic recurrence after ablation therapies and/or surgical resection is the main cause of late death of patients with HCC. In current study, local recurrence was found to be more frequent after RFA than after HR. Local recurrences after RFA may be attributable to insufficient ablation of the primary tumor and/or the presence of tumor venous invasion in the adjacent liver. Surgical resection could remove the primary tumor and venous tumor thrombi [12]. This may explain the better outcomes following HR.

Table 3: Studies comparing RFA versus HR for $\mathrm{HCC} \leq \mathbf{3} \mathrm{cm}$

\begin{tabular}{|c|c|c|c|c|c|c|c|c|c|}
\hline \multirow[t]{2}{*}{ Author } & \multirow[t]{2}{*}{ Treatment } & \multirow{2}{*}{$\begin{array}{l}\text { No. of } \\
\text { patients }\end{array}$} & \multicolumn{3}{|c|}{ Survival (\%) } & \multicolumn{3}{|c|}{ Disease-free survival (\%) } & \multirow[t]{2}{*}{$P$-value } \\
\hline & & & 1-year & 3-year & 5-year & 1-year & 3-year & 5-year & \\
\hline \multirow[t]{2}{*}{ Vivarelli } & RFA & 22 & 89 & -- & 50 & 70 & 34 & -- & NS \\
\hline & $\mathrm{HR}$ & 21 & 89 & -- & 79 & 84 & 67 & -- & \\
\hline \multirow[t]{2}{*}{ Guglielmi } & RFA & 32 & 91 & 50 & 29 & 72 & 36 & 36 & NS \\
\hline & $\mathrm{HR}$ & 31 & 89 & 78 & 54 & 80 & 58 & 19 & \\
\hline \multirow[t]{2}{*}{ Hiraoka } & RFA & 105 & 95.1 & 87.8 & 59.3 & 87.5 & 58.7 & 24.6 & NS \\
\hline & $\mathrm{HR}$ & 59 & 98.1 & 91.4 & 59.4 & 91.4 & 64.3 & 22.4 & \\
\hline
\end{tabular}

RFA: radiofrequency ablation.HR: hepatic resection. NS: not significant 
As regards the distant recurrence, no differences were found between the two groups. This fnding is reasonable because the occurrence of distant recurrence is correlated with the host factors and initial tumor factors [32], and the treatment does not affect this outcome.

Although the overall rate of postoperative morbidity was $32.5 \%$ in patients treated with HR, which is significantly higher than in those treated with RFA. However, these rates do not translate into an increase in mortality.

The results of this meta-analysis should be interpreted with caution for several reasons. First, the majority of data in the present study comes from NRCTs, and the overall level of clinical evidence is low. Second, there are important heterogeneity between two groups. This could be due to a bias in patient selection in several series in terms of patient demographics and tumor characteristics. Patients undergoing RFA had a few less favourable characteristics such as old age, multiple nodules, severe chronic liver disease, high serum level of alpha-fetoprotein and aspartate aminotransferase level [22,25,27,28]. However, Guglielmi et al. [27] found that these biases did not influence the statistical analysis in the subgroups and in the multivariate analyses. We applied a random effect model to take between study variation into consideration. This does not necessarily rule out the effect of heterogeneity between studies, but one may expect a very limited influence.

Third, RFA can be performed by percutaneous, laparoscopic or open approaches. Laparoscopic and open approaches increase the chance of detection of unknown intrahepatic and extrahepatic tumors because they allow complete abdominal exploration and intraoperative ultrasound assessment. The additional advantages of open and laparoscopic approaches are the accurate placement of electrodes and the possible treatment of tumors in percutaneously inaccessible areas of the liver and tumors in close proximity to or invading the adjacent organs [6]. On the other hand, several different RFA systems were used in the treatment centers, such as RITA Medical System (Mountain View, CA), Radionics (Burlington, MA) and Valleylab (Boulder, CO). Different approaches and RFA systems would also impact on the pooling of data and interpretation of results. Unfortunately, we failed to find any study that compared the outcomes of different approaches and RFA systems on therapy efficacy of HCC. Thus, we were not able to assess the influence of these factors.

Vascular invasion is a well-established prognostic indicator of HCC. Considering that vascular invasion was less frequent in tumors $\leq 3 \mathrm{~cm}$ [33], this may explain equivalent survival outcome between two groups, as reported in 3 trials. RFA appears to be an effective alternative treatments modality for $\mathrm{HCC} \leq 3 \mathrm{~cm}$. However, the only three studies containing 270 patients make the interpretation of these results insufficient. Recently, in a large, prospective study from the Liver Cancer Study Group of Japan, 7185 patients with no more than 3 tumors $(\leq 3 \mathrm{~cm})$ were classified into either a resection $(\mathrm{n}=2857)$, RFA $(\mathrm{n}=$ $3022)$, or PEI group $(\mathrm{n}=1306)$. The comparison of all three groups showed that surgical resection may be superior to ablation with respect to the prevention of recurrence [20]. Thus, the efficacy compared to HR or ablation in the treatment for $\mathrm{HCC} \leq 3 \mathrm{~cm}$ still is a matter of discussion and further studies are required to provide more adequate data answer this question.

\section{Conclusions}

HR was superior to RFA in the treatment of patients with small HCC eligible for surgical treatments, particularly for tumors $>3 \mathrm{~cm}$. However, the findings have to be carefully interpreted due to the lower level of evidence. Further RCT are needed to define the exact value of HR and RFA for small $\mathrm{HCC}$, even for tumors $\leq 3 \mathrm{~cm}$.

\section{Competing interests}

The authors declare that they have no competing interests.

\section{Authors' contributions}

YZhou participated in the design and coordination of the study, carried out the critical appraisal of studies and wrote the manuscript. BL, DX, ZY and developed the literature search, carried out the extraction of data, assisted in the critical appraisal of included studies and assisted in writing up. YZhao and FX carried out the statistical analysis of studies. JY interpreted data, corrected and approve the manuscript. All authors read and approved the final manuscript.

\section{Author Details}

1Department of Hepato-Biliary-Pancreato-Vascular Surgery, the First affiliated Hospital of Xiamen University, Xiamen, China, ${ }^{2}$ Department of Health Statistics, Second Military Medical University, Shanghai, China, ${ }^{3}$ Department of

Molecular Oncology, Eastern Hepatobiliary Surgery Hospital, Second Military Medical University, Shanghai, China and 4Department of Special Treatment, Eastern Hepatobiliary Surgery Hospital, Second Military Medical University, Shanghai, China

Received: 28 December 2009 Accepted: 9 July 2010

Published: 9 July 2010

\section{References}

1. Llovet JM, Burroughs A, Bruix J: Hepatocellular carcinoma. Lancet 2003 362:1907-1917.

2. Befeler AS, Hayashi PH, Di Bisceglie AM: Liver transplantation for hepatocellular carcinoma. Gastroenterology 2005, 128:1752-1764.

3. Zhou XD, Tang ZY: Cryotherapy for primary liver cancer. Semin Surg Oncol 1998, 14:171-174

4. Danila M, Sporea I, Sirli R, Popescu A: Percutaneous ethanol injection therapy in the treatment of hepatocarcinoma--results obtained from a series of 88 cases. J Gastrointestin Liver Dis 2009, 18:317-322.

5. Huo TI, Huang YH, Huang HC, Wu JC, Lee PC, Chang FY, Lee SD: Fever and infectious complications after percutaneous acetic acid injection therapy for hepatocellular carcinoma: incidence and risk factor analysis. J Clin Gastroenterol 2006, 40:639-642.

6. Lau WY, Lai EC: The current role of radiofrequency ablation in the management of hepatocellular carcinoma: a systematic review. Ann Surg 2009, 249:20-25.

7. Kawamoto C, Ido K, Isoda N, Hozumi M, Nagamine N, Ono K, Sato Y, Kobayashi Y, Nagae G, Sugano K: Long-term outcomes for patients with solitary hepatocellular carcinoma treated by laparoscopic microwave coagulation. Cancer 2005, 103:985-993. 
8. Pelletier G, Roche A, Ink O, Anciaux ML, Derhy S, Rougier P, Lenoir C, Attali $P$, Etienne JP: A randomized trial of hepatic arterial chemoembolization in patients with unresectable hepatocellular carcinoma. J Hepatol 1990, 11:181-184

9. Bruix J, Sherman M: Management of hepatocellular carcinoma. Hepatology 2005, 42:1208-1236.

10. Bouza C, López-Cuadrado T, Alcázar R, Saz-Parkinson Z, Amate JM: Metaanalysis of percutaneous radiofrequency ablation versus ethanol injection in hepatocellular carcinoma. BMC Gastroenterol 2009, 9:31.

11. Yao FY, Ferrell L, Bass NM, Watson JJ, Bacchetti P, Venook A, Ascher NL, Roberts JP: Liver transplantation for hepatocellular carcinoma: expansion of the tumor size limits does not adversely impact survival. Hepatology 2001, 33:1394-1403.

12. Wakai T, Shirai Y, Suda T, Yokoyama N, Sakata J, Cruz PV, Kawai H, Matsuda Y, Watanabe M, Aoyagi Y, Hatakeyama K: Long-term outcomes of hepatectomy vs percutaneous ablation for treatment of hepatocellular carcinoma $<$ or $=4 \mathrm{~cm}$. World J Gastroenterol 2006, 12:546-552.

13. Lü MD, Kuang M, Liang LJ, Xie XY, Peng BG, Liu GJ, Li DM, Lai JM, Li SQ: Surgical resection versus percutaneous thermal ablation for earlystage hepatocellular carcinoma: a randomized clinical trial. Zhonghua YiXue Za Zhi 2006, 86:801-805

14. Schwarz RE, Smith DD: Trends in local therapy for hepatocellular carcinoma and survival outcomes in the US population. Am J Surg 2008, 195:829-836.

15. Ogihara M, Wong LL, Machi J: Radiofrequency ablation versus surgical resection for single nodule hepatocellular carcinoma: Long-term outcomes. HPB (Oxford) 2005, 7:214-221.

16. Ueno S, Sakoda M, Kubo F, Hiwatashi K, Tateno T, Baba Y, Hasegawa S, Tsubouchi H, Kagoshima Liver Cancer Study Group: Surgical resection versus radiofrequency ablation for small hepatocellular carcinomas within the Milan criteria. J Hepatobiliary Pancreat Surg 2009, 16:359-366.

17. Kudo $M$, Chung $\mathrm{H}$ : Single HCC between 2 and $5 \mathrm{~cm}$ : the grey zone: Hepatologist's perspective. J Hepatobiliary Pancreat Surg 2009 in press.

18. Ikeda K, Kobayashi M, Saitoh S, Someya T, Hosaka T, Sezaki H, Suzuki Y, Suzuki F, Akuta N, Arase Y, Kumada H, Matsuda M, Hashimoto M, Watanabe G: Cost-effectiveness of radiofrequency ablation and surgical therapy for small hepatocellular carcinoma of $3 \mathrm{~cm}$ or less in diameter. Hepatol Res 2005, 33:241-249.

19. Hasegawa K, Makuuchi M, Takayama T, Kokudo N, Arii S, Okazaki M, Okita K, Omata M, Kudo M, Kojiro M, Nakanuma Y, Takayasu K, Monden M, Matsuyama Y, Ikai I: Surgical resection vs. percutaneous ablation for hepatocellular carcinoma: a preliminary report of the Japanese nationwide survey. J Hepatol 2008, 49:589-594.

20. Hasegawa K, Kokudo N, Sano K, Makuuchi M: Single HCC between 2 and $5 \mathrm{~cm}$ : the grey zone: Surgeon's perspective. J Hepatobiliary Pancreat surg 2009 in press.

21. Vivarelli M, Guglielmi A, Ruzzenente A, Cucchetti A, Bellusci R, Cordiano C, Cavallari A: Surgical resection versus percutaneous radiofrequency ablation in the treatment of hepatocellular carcinoma on cirrhotic liver. Ann Surg 2004, 240:102-107.

22. Hong SN, Lee SY, Choi MS, Lee JH, Koh KC, Paik SW, Yoo BC, Rhee JC, Choi D, Lim HK, Lee KW, Joh JW: Comparing the outcomes of radiofrequency ablation and surgery in patients with a single small hepatocellular carcinoma and well-preserved hepatic function. J Clin Gastroenterol 2005, 39:247-252.

23. Cho CM, Tak WY, Kweon YO, Kim SK, Choi YH, Hwang YJ, Kim YI: The comparative results of radiofrequency ablation versus surgical resection for the treatment of hepatocellular carcinoma. Korean $J$ Hepatol 2005, 11:59-71.

24. Abu-Hilal M, Primrose JN, Casaril A, McPhail MJ, Pearce NW, Nicoli N: Surgical resection versus radiofrequency ablation in the treatment of small unifocal hepatocellular carcinoma. J Gastrointest Surg 2008, 12:1521-1526

25. Chen MS, Li JQ, Zheng Y, Guo RP, Liang HH, Zhang YQ, Lin XJ, Lau WY: A prospective randomized trial comparing percutaneous local ablative therapy and partial hepatectomy for small hepatocellular carcinoma. Ann Surg 2006, 243:321-328.

26. Lupo L, Panzera P, Giannelli G, Memeo M, Gentile A, Memeo V: Single hepatocellular carcinoma ranging from 3 to $5 \mathrm{~cm}$ : radiofrequency ablation or resection? HPB (Oxford) 2007, 9:429-434.

27. Guglielmi A, Ruzzenente A, Valdegamberi A, Pachera S, Campagnaro T, D'Onofrio M, Martone E, Nicoli P, lacono C: Radiofrequency ablation versus surgical resection for the treatment of hepatocellular carcinoma in cirrhosis. J Gastrointest Surg 2008, 12:192-8.

28. Hiraoka A, Horiike N, Yamashita Y, Koizumi Y, Doi K, Yamamoto Y, Hasebe A, Ichikawa S, Yano M, Miyamoto Y, Ninomiya T, Otomi Y, Kokame M, Iwamura T, Ishimaru Y, Sogabe I, Kashihara K, Nishiura S, Ootani H, Takamura K, Kawasaki H: Efficacy of radiofrequency ablation therapy compared to surgical resection in 164 patients in Japan with single hepatocellular carcinoma smaller than $3 \mathrm{~cm}$, along with report of complications. Hepatogastroenterology 2008, 55:2171-2174.

29. Montorsi M, Santambrogio R, Bianchi P, Donadon M, Moroni E, Spinelli A, Costa M: Survival and recurrences after hepatic resection or radiofrequency for hepatocellular carcinoma in cirrhotic patients: a multivariate analysis. J Gastrointest Surg 2005, 9:62-67.

30. Santambrogio R, Opocher E, Zuin M, Selmi C, Bertolini E, Costa M, Conti M, Montorsi M: Surgical Resection Versus Laparoscopic Radiofrequency Ablation in Patients With Hepatocellular Carcinoma and Child-Pugh Class A Liver Cirrhosis. Ann Surg Oncol 2009, 16:3289-3298.

31. Mathurin P, Raynard B, Dharancy S, Kirzin S, Fallik D, Pruvot FR, Roumilhac D, Canva V, Paris JC, Chaput JC, Naveau S: Meta-analysis: evaluation of adjuvant therapy after curative liver resection for hepatocellular carcinoma. Aliment Pharmacol Ther 2003, 17:1247-1261.

32. Okuwaki Y, Nakazawa T, Shibuya A, Ono K, Hidaka H, Watanabe M, Kokubu $\mathrm{S}$, Saigenji K: Intrahepatic distant recurrence after radiofrequency ablation for a single small hepatocellular carcinoma: risk factors and patterns. J Gastroenterol 2008, 43:71-78.

33. Adachi E, Maeda T, Kajiyama K, Kinukawa N, Matsumata T, Sugimachi K, Tsuneyoshi M: Factors correlated with portal venous invasion by hepatocellular carcinoma: univariate and multivariate analyses of 232 resected cases without preoperative treatments. Cancer 1996, 77:2022-2031.

\section{Pre-publication history}

The pre-publication history for this paper can be accessed here: http://www.biomedcentral.com/1471-230X/10/78/prepub

doi: 10.1186/1471-230X-10-78

Cite this article as: Zhou et al., Meta-analysis of radiofrequency ablation versus hepatic resection for small hepatocellular carcinoma BMC Gastroenterology 2010, 10:78

\section{Submit your next manuscript to BioMed Central and take full advantage of:}

- Convenient online submission

- Thorough peer review

- No space constraints or color figure charges

- Immediate publication on acceptance

- Inclusion in PubMed, CAS, Scopus and Google Scholar

- Research which is freely available for redistribution

Submit your manuscript at www.biomedcentral.com/submit
C Biomed Central 